\title{
Phenotyping and genotyping methods applied to investigate the relatedness of Brazilian isolates of Enterobacter cloacae
}

\author{
A.L.C. Darini ${ }^{1}$, \\ V.D. Magalhães \\ C.L. Levy ${ }^{3}$, \\ A.L. Barth 4 and \\ A.L. Coscina 2
}

\author{
1Departamento de Análises Clínicas, Toxicológicas e Bromatológicas, \\ Faculdade de Ciências Farmacêuticas de Ribeirão Preto, \\ Universidade de São Paulo, Ribeirão Preto, SP, Brasil \\ ${ }^{2}$ Laboratório de Biologia Molecular, Hospital Israelita Albert Einstein, \\ São Paulo, SP, Brasil \\ ${ }^{3}$ Departamento M édico, Laboratórios Pfizer, Guarulhos, SP, Brasil \\ ${ }^{4}$ Unidade de Microbiologia, Hospital de Clínicas de Porto Alegre, \\ Porto Alegre, RS, Brasil
}

\section{Correspondence \\ V.D. Magalhães \\ Laboratório de Biologia Molecular Hospital Israelita Albert Einstein \\ Av. Albert Einstein, 627 \\ 05651-901 São Paulo, SP \\ Brasil \\ Fax: + 55-11-842-2834 \\ E-mail: vanda@ einstein.br}

Publication supported by FAPESP

Received January 18, 1999 Accepted July 12, 1999

\section{Abstract}

In order to evaluate the resolving power of several typing methods to identify relatedness among Brazilian strains of Enterobacter cloacae, we selected twenty isolates from different patients on three wards of a University Hospital (Orthopedics, Nephrology, and Hematology). Traditional phenotyping methods applied to isolates included biotyping, antibiotic sensitivity, phage-typing, and $\mathrm{O}$-serotyping. Plasmid profile analysis, ribotyping, and macrorestriction analysis by pulsed-field gel electrophoresis (PFGE) were used as genotyping methods. Sero- and phage-typing were not useful since the majority of isolates could not be subtyped by these methods. Biotyping, antibiogram and plasmid profile permitted us to classify the samples into different groups depending on the method used, and consequently were not reliable. Ribotyping and PFGE were significantly correlated with the clinical epidemiological analysis. PFGE did not type strains containing nonspecific DNase. Ribotyping was the most discriminative method for typing Brazilian isolates of E. cloacae.

In recent years, Enterobacter cloacae has been increasingly recognized as a significant cause of infection in hospitalized patients with serious underlying disease (1). Although outbreaks due to nosocomial acquisition of E. cloacae have been reported by a number of investigators $(2,3)$, it has also been reported that endogenous E. cloacae may be the source of infection, even during longterm hospitalization (4). Accordingly, there is a need for persistent surveillance of nosocomial infections caused by E. cloacae in

\section{Key words}

- Enterobacter cloacae

- Phage-typing

- Serotyping

- Ribotyping

- Pulsed-field gel

electrophoresis

- Nosocomial infection order to distinguish among isolates involved in outbreaks, person-to-person transmission, and endogenous flora.

In this study, we compared the discriminatory power of phenotypic and genotypic typing methods applied to Brazilian E. cloacae strains. The isolates were cultured from 17 patients admitted to three different wards, who were suspected of having acquired $E$. cloacae at the University Hospital of Ribeirão Preto. These patients had contact with each other on each ward (Orthopedics (ORTH), 
Nephrology (NEPH), and Hematology (HEM)) from May to November 1992. The diagnosis of nosocomial infection was based on Center for Disease Control guidelines. One patient on each ward, who was not implicated in hospital-borne infection, was selected as control.

Identification of bacteria (Neg Combo Panel Type 1), biotyping, and susceptibility to antibiotics were performed using the MicroScan System (Baxter Diagnostics, Inc., Deerfield, IL, USA), following the manufacturer's instructions. The biotype was a 7digit number (bionumber) assigned to each isolate according to its response to 21 biochemical tests. The antibiogram type (designated by a lower case letter) was determined by the growth response of isolates to 18 antimicrobial agents. Phage-typing was performed as previously described by Gaston (5) with a panel of 25 phage. After incuba- tion at $32^{\circ} \mathrm{C}$ for $18 \mathrm{~h}$ phage reactions were scored as follows: strong reaction $(>50$ plaques), shown in capital letters; intermediate reaction ( $\leq 50$ plaques), shown in lower case letters; or weak reaction, shown in parentheses. O-serotyping was performed according to the method described by Gaston et al. (6), using six pools of "O" specific monovalent sera.

Genotype-based methods included plasmid profile, pulsed-field gel electrophoresis (PFGE), and ribotyping. Plasmids were extracted by a boiling method (7) and separated on a $0.8 \%$ agarose gel in TBE buffer ( $89 \mathrm{mM}$ Tris, $89 \mathrm{mM}$ boric acid, $2 \mathrm{mM}$ EDTA, pH 8.3). PFGE was carried out in a Gene Navigator apparatus (Pharmacia Biotech, Uppsala, Sweden), on 1.5\% agarose gels. Genomic DNA was prepared in agarose plugs as described by Haertl and Bandlow (8). First, the blocks were submit-

Table 1 - Phenotypic and genotypic characteristics of E. cloacae isolates.

ORTH, Orthopedics unit; NEPH, Nephrologic unit; HEM, Hematology unit; NT, non-typable.

\begin{tabular}{|c|c|c|c|c|c|c|c|c|c|c|}
\hline $\begin{array}{l}\text { Isolate } \\
\text { no. }\end{array}$ & $\begin{array}{l}\text { Date of } \\
\text { isolation }\end{array}$ & Patient & $\begin{array}{c}\text { Source/ } \\
\text { unit }\end{array}$ & Biotype & $\begin{array}{l}\text { Antibio- } \\
\text { type }\end{array}$ & $\begin{array}{l}\text { Sero- } \\
\text { type }\end{array}$ & $\begin{array}{c}\text { Phage- } \\
\text { type }\end{array}$ & $\begin{array}{c}\text { Plasmid } \\
\text { profile }\end{array}$ & $\begin{array}{l}\text { Ribo- } \\
\text { type }\end{array}$ & PFGE \\
\hline 1 & May 8 & $\mathrm{RC}$ & Wound/ORTH & 7730317-III & $a$ & NT & NT & P1 & S1 & N1 \\
\hline 2 & May 14 & DS & Wound/ORTH & 7730317-III & $\mathrm{b}$ & 19 & EMQ & P1 & $\mathrm{S1}$ & NT \\
\hline 4 & May 15 & $\mathrm{EF}$ & Wound/ORTH & 7730317-III & C & 07 & NT & $\mathrm{P} 2$ & $\mathrm{~S} 2$ & $\mathrm{~N} 2$ \\
\hline 5 & May 15 & $\mathrm{JC}$ & Wound/ORTH & 7730337-IV & a & NT & NT & - & S3 & N3 \\
\hline 6 & $\mathrm{~J}$ un 11 & $\mathrm{AF}$ & Wound/ORTH & 7710337-II & a & $\mathrm{V}$ & (h) & $\mathrm{P} 1$ & $\mathrm{~S} 4$ & N4 \\
\hline 7 & J ul 15 & $\mathrm{RI}$ & Abscess/ORTH & 7730337-IV & a & 13 & (b)CF(g)J & P1 & S5 & N5 \\
\hline 8 & Sept 11 & IG & Wound/ORTH & 7730337-IV & a & AA & $A b E(f)(g) I$ & - & S6 & N6 \\
\hline 10 & May 18 & $J F$ & Urine/NEPH & 7710317-I & d & III & NT & P3 & S3 & N3 \\
\hline 11 & J un 16 & SF & Urine/NEPH & 7510337-VII & g & 23 & (I) & P4 & S8 & NT \\
\hline 12 & J un 16 & $J P$ & Urine/NEPH & 7710317-I & d & NT & NT & P3 & S3 & N3 \\
\hline 14 & J un 17 & WV & Catheter/NEPH & 7310317-V & $\mathrm{h}$ & 04 & (I) & $\mathrm{P} 1$ & S9 & NT \\
\hline 18 & Oct 23 & NS & Urine/NEPH & 7710337-II & $\mathrm{i}$ & PA & $M$ & P5 & $\mathrm{S} 10$ & NT \\
\hline 19 & Nov 3 & NA & Wound/NEPH & 7710337-II & e & NT & NT & P4 & $\mathrm{S} 11$ & $\mathrm{~N} 11$ \\
\hline 20 & Aug 12 & $A B$ & Urine/NEPH & |7710317 & j & PA & NT & $\mathrm{P} 1$ & S11 & N11 \\
\hline 30 & J un 8 & MR & Urine/NEPH & I710317 & e & NT & NT & P1 & S4 & N4 \\
\hline 31 & J ul 15 & MP & Urine/HEM & 771037-II & e & IV & NT & P1 & S5 & N5 \\
\hline 32 & J ul 23 & AT & Sputum/HEM & 7750237-VI & $f$ & NT & (g) & P4 & S6 & N6 \\
\hline 34 & Aug 5 & $M L$ & Catheter/HEM & 7710317-I & e & NT & NT & P1 & S6 & N6 \\
\hline 37 & Sept 25 & GB & Catheter/HEM & 7510337-VII & i & 19 & NT & P7 & S15 & NT \\
\hline 38 & Nov 3 & ER & Oropharynx/HEM & 7610337-VIII & e & NT & NT & P1 & S15 & NT \\
\hline
\end{tabular}


ted to a pre-run at $100 \mathrm{~V}$ for $60 \mathrm{~min}$ at $7^{\circ} \mathrm{C}$, with pulse time of $0.2 \mathrm{~s}$ (interpolate) before restriction digestion. Thereupon, the blocks were digested with NotI and submitted to PFGE as follows: phase I, $25 \mathrm{~s}$ for $20 \mathrm{~h}$; phase II, $5 \mathrm{~s}$ for $4 \mathrm{~h}$; phase III, $0.5 \mathrm{~s}$ for $1 \mathrm{~h}$. Chromosomal DNA for ribotyping was extracted according to the method described by Mekalanos (9). DNA was cleaved by the restriction enzyme SmaI. A digoxigenin-labeled plasmid (pKK3535) was used as a probe (10). Labeling and detection followed the recommendations of BoehringerMannheim, Mannheim, Germany. Table 1 summarizes the results of all typing methods. All isolates were typed three times in order to assess reproducibility.

Eight different biovar patterns were identified among the 20 isolates. Biovar number $\mathrm{I}$, the most common bio-type, was found almost exclusively in patients on the NEPH ward, but also in one patient on the HEM unit. Patterns III and IV were only observed in patients on the ORTH ward. The clustering of specific biotyping on one unit suggests cross-contamination. Biovar number II was identified in patients from the three wards. This result disagrees with clinical epidemiological data, since patients from different units had never shared staff or devices, and had never been in contact.

The isolates were classified into 10 groups according to the profile of resistance. Antibiotype a, one of the most prevalent (5 cases), was found exclusively in isolates from patients on the ORTH ward. On the other hand, antibiotype e, also found in 5 cases, was detected in samples from NEPH and HEM units.

The results of biotyping and antibiogram grouped the isolates differently, raising doubts over which method should be considered for the purpose of an epidemiological investigation. The unsuitable character of biotyping alone in discriminating strains has been described (11). Antibiotic susceptibility profiles also have some significant limi- tations (12). The main drawback of the method is an inherent four-fold variation in the range of minimal inhibitory concentration results, which can misclassify the organism (13).

Phage- and serotyping were of lesser value since they failed to classify 12 and 11 isolates, respectively.

The plasmid content of the bacteria showed 7 different plasmid profiles. However, a 72-kb element was detected in almost every sample. This large plasmid could be described as a highly promiscuous element, useless for discriminating strains. The plasmid profile called P3 (isolates 10 and 12) showed correlation with the resistance profile (antibiotype d). Isolates 5 and 8 did not have plasmids. It is noteworthy that extrachromosomal elements can be easily acquired or lost, depending on the antibiotic pressure. Alternatively, a plasmid can integrate into the chromosomal DNA, being undetectable by the usual extraction techniques (14).

Ribotyping after digestion of chromosomal DNA with SmaI yielded approximately 10 bands per lane, and distinguished 15 strains (Figure 1). The data suggested crosscontamination between patients who had been admitted to the same wards: patients 1 and 2 on the ORTH unit, patients 10 and 12 on the NEPH unit, patients 19 and 20, also on the NEPH unit, patients 32, 34, 37 and 38 on the HEM unit. Ribotyping discriminated

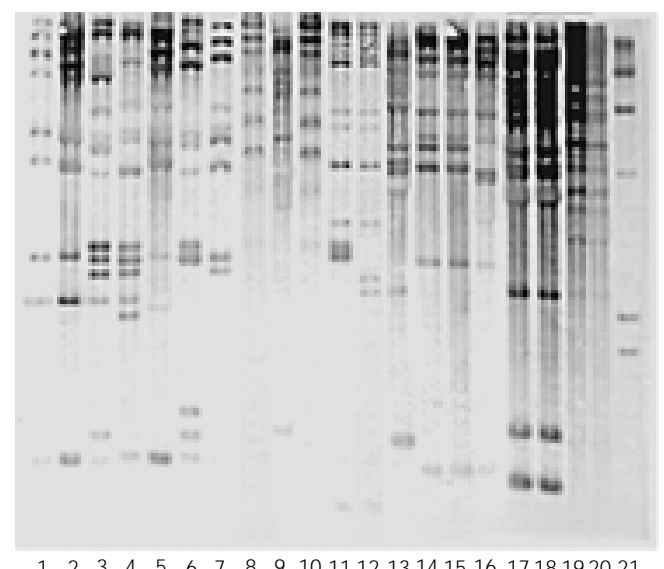

Figure 1 - Smal ribotypes of $\mathrm{E}$. cloacae strains. 1, EC1; 2, EC2; 3, EC4; 4, EC5; 5, EC6; 6, EC7; 7, EC8; 8, EC10; 9, EC11; 10, EC12; 11, EC14; 12, EC18; 13, EC30; 14, EC19; 15, EC20; 16, EC31; 17, ЕC32; 18, ЕC34; 19, EC37; 20, EC38; 21, molecular weight marker, $\lambda$ HindIII. 
the E. cloacae isolate of the control patient on each ward $(6,30$, and 31$)$. Other patients $(4,5,7,8,11,14$, and 18), who also had nosocomial infection by E. cloacae, showed different ribotypes. These results suggest that even if these patients had acquired the bacteria at the hospital, they were not involved in a cross-contamination event. The ribotyping patterns obtained were reproducible in three independent experiments. In order to achieve a better discriminatory power, we also used $E c o$ RI, which further confirmed the results with SmaI. The use of EcoRI, BamHI, HindIII, and $P v u \mathrm{II}$, independently, has been found to be very useful for discriminating among strains of $E$. cloacae by ribotyping $(15,16)$.

Although the band patterns achieved after NotI digestion of chromosomal DNA were complex for visual analysis, PFGE grouped the samples into 11 classes. The results agreed with those obtained with ribotyping. Six isolates (numbers 2, 11, 14, 18, 37, and 38) could not be typed by PFGE because of DNase contamination. We were not successful in trying to avoid the action of DNase by using different growth and running conditions. Similar problems were also reported by other researchers who suggested the activity of a nonspecific nuclease produced by some strains to be responsible for this effect (17).

There is no consensus about interpreting DNA restriction patterns generated by ribotyping or PFGE. Nevertheless, Tenover et al. (18) suggested some guidelines for interpreting chromosomal DNA restriction patterns produced by PFGE that could also be used for ribotyping. They observed that point mutations, insertions or deletions could result in the creation or loss of a restriction site, or a difference in the size of a fragment, resulting in altered patterns. Moreover, care should be taken concerning bands created by partial digestion, and the amount of DNA loaded per lane, which could slightly shift band position. In general, when each and every band in one lane matches the bands in another, the strains are considered to be identical. Strains can be judged to be closely related when they share most bands. Dice's coefficient of similarity could be used for this purpose, since it takes into account the number of shared bands and the total number of fragments obtained with the restriction enzyme (18).

The results obtained with any strain typing method must always be evaluated within the context of the available clinical and epidemiological data. In general, phenotypic methods discriminated poorly and often produced inconsistent results. Accordingly, changes in lipopolysaccharide, which functions as a bacteriophage receptor, may affect the sensitivity of strains to phages. O-serotyping showed spontaneous agglutination in saline and subtle alterations of antigen epitopes, leading to nonspecific reactions to different sera. Thus, sero- and phage-typing are frequently inadequate for the recognition of clonal groups. Genetic heterogeneity within the same serotype has been described (19). The combination of two or more phenotypic typing methods has been proposed as an essential requirement for discriminating between strains of E. cloacae (4). Although we tried different combinations of phenotype-based methods, the results grouped isolates that did not have obvious connections and subdivided others that were linked on the basis of epidemiological data. This observation was also reported by others (20). Traits that could have their expression regulated or have unstable features, like phenotypic characteristics or plasmid profile, respectively, do not always associate with known epidemiological facts.

Among the genotype-based methods, PFGE could not be used to type all samples of $E$. cloacae because of DNase contamination. However, this technique has been widely used as a tool for epidemiologic surveillance of different bacterial genera, including $E$. cloacae $(8,18)$. In Brazil, PFGE has been successfully applied to analyze the spread of 
Acinetobacter baumannii among three hospitals located in São Paulo (21). Ribotyping has also been extensively used to discriminate among unrelated and epidemiologically related isolates in Brazil (22) and abroad (14-16). In this work, ribotyping was the most helpful method for the investigation of cross-contamination with E. cloacae. The information obtained with this technique agreed with our epidemiological data and the method was relatively simple to perform, yielding reproducible results.

\section{Acknowledgments}

We thank Dr. T.L. Pitt, Central Public Health Laboratory - Laboratory of Hospital Infection, London, who kindly provided the sero- and phage-typing of the isolates. We are grateful to Dr. Orlando Ferreira and Patricia Severino for a critical reading of the manuscript and helpful discussions.

\section{References}

1. Sanders WE \& Sanders CC (1997). Enterobacter spp.: pathogens poised to flourish at the turn of the century. Clinical Microbiology Reviews, 10: 220-241.

2. Acolet $D$, Ahmet $Z$, Houang E, Hurley R \& Kaufmann ME (1994). Enterobacter cloacae in a neonatal intensive care unit: account of an outbreak and its relationship to use of third generation cephalosporins. J ournal of Hospital Infection, 28: 273-286.

3. Mayhall CG, Lamb VA, Gayle J r WE \& Haynes J r BW (1979). Enterobacter cloacae septicemia in a burn center: epidemiology and control of an outbreak. J ournal of Infectious Diseases, 139: 166-171.

4. Flynn DM, Weinstein RA, Nathan C, Gaston MA \& Kabins SA (1987). Patient endogenous flora as the source of nosocomial Enterobacter in cardiac surgery. J ournal of Infectious Diseases, 156: 363368.

5. Gaston MA (1987). Isolation and selection of a bacteriophage-typing for Enterobacter cloacae. J ournal of Medical Microbiology, 24: 285-290.

6. Gaston MA, Bucher C \& Pitt TL (1983). Oserotyping scheme for Enterobacter cloacae. J ournal of Clinical Microbiology, 18: 1079-1083.

7. Kado CI \& Liu ST (1981). Rapid procedure for detection and isolation of large and small plasmids. J ournal of Bacteriology, 145: 1363-1373.

8. Haertl R \& Bandlow G (1993). Epidemiological fingerprint of Enterobacter cloacae by small-fragment restriction endonuclease analysis and pulsed-field gel electrophoresis of genomic restriction fragments. J ournal of Clinical Microbiology, 31: 128-133.

9. Mekalanos JJ (1983). Duplication and amplification of toxin genes in Vibrio chole- rae. Cell, 35: 253-263.

10. Brosius J, Ullrich A, Raker MA, Dull TJ, Gutell RR \& Noller HF (1981). Construction and fine mapping of recombinant plasmids containing the $\mathrm{rm} B$ ribossomal RNA operon of E. coli. Plasmid, 6: 112118.

11. Achtman $M$, Heuzenroeder $M$, Kusecek B, Ochman H, Caugant D, Selander RK, Vaisanen-Rhen V, Korhonen TK, Stuart S, Orskov RK \& Orskov I (1986). Clonal analysis of Escherichia coli O2:K1 isolated from diseased humans and animals. Infection and Immunity, 51: 268-276.

12. Tenover FC, Arbeit R \& Archer G (1994). Comparison of traditional and molecular methods of typing isolates of Staphylococcus aureus. J ournal of Clinical Microbiology, 32: 407-415.

13. Mickelsen PA, Plorde JJ, Gordon KP, Hargiss C, McClure J, Schoenknert FD, Condie F, Tenover FC \& Tompkins LS (1985). Instability of antibiotic resistance in a strain of Staphylococcus epidermidis isolated from an outbreak of prosthetic valve endocarditis. J ournal of Infectious Diseases, 152: 50-58.

14. Weischer M \& Kolmos HJ (1993). Ribotyping of selected isolates of Enterobacter cloacae and clinical data related to biotype, phage type, O-serotype, and ribotype. Acta Pathologica Microbiologica et Immunologica Scandinavica, 101: 879886.

15. Grattard F, Pozzeto B, Berthelot P, Rayet I, Ros A, Lauras B \& Gaudin OG (1994). Arbitrarily primed $P C R$, ribotyping and plasmid pattem analysis applied to investigation of a nosocomial outbreak due to E. cloacae in a neonatal intensive care unit. J ournal of Clinical Microbiology, 32: 596-602.
16. Garaizar J , Kaufman ME \& Pitt TL (1991). Comparison of ribotyping with conventional methods for the type identification of Enterobacter cloacae. J ournal of Clinical Microbiology, 29: 1303-1307.

17. Baggesen DL, Wegener ZHC \& Christensen J P (1996). Typing of Salmonella enterica Saintpaul: An outbreak investigation. Acta Pathologica Microbiologica et Immunologica Scandinavica, 104 411-418.

18. Tenover FC, Arbeit RD, Goering RV Mickelsen PA, Murray BE, Persing DH \& Swaminathan B (1995). Interpreting chromosomal DNA restriction patterns produced by pulsed-field gel electrophoresis: Criteria for bacterial strain typing. J ournal of Clinical Microbiology, 33: 2233-2239.

19. Alos J -I, Lambert T \& Courvalin P (1993). Comparison of two molecular methods for tracing nosocomial transmission of Escherichia coli $\mathrm{K} 1$ in a neonatal unit. J ournal of Clinical Microbiology, 31: 17041709.

20. Pfaller MA \& Herwaldt LA (1997). The clinical microbiology laboratory and infection control: emerging pathogens, antimicrobial resistance, and new technology. Clinical Infectious Diseases, 25: 858-870.

21. Sader HS, Mendes CF, Pignatari AC \& Pfaller MA (1996). Use of macrorestriction analysis to demonstrate interhospital spread of multiresistant Acinetobacter baumannii in São Paulo, Brazil. Clinical Infectious Diseases, 23: 631-634.

22. Dalla-Costa LM, Irino K, Rodrigues J Rivera IN \& Trabulsi LR (1998). Characterisation of diarrhoeagenic Escherichia coli clones by ribotyping and ERIC-PCR. J ournal of Medical Microbiology, 47: 227 234. 